Supporting Information

\title{
Triptycene derived Photoresponsive Fluorescent Azo-Polymer as Chemosensor for Picric Acid Detection
}

\author{
Mosim Ansari, ${ }^{\dagger}$ Ranajit Bera, $^{\dagger}$ Snehasish Mondal ${ }^{\dagger}$ and Neeladri Das* ${ }^{*} \dagger$ \\ †Department of Chemistry, Indian Institute of Technology Patna, 801106, Bihar, India \\ *Corresponding author, e-mail: neeladri2002@yahoo.co.in, neeladri@iitp.ac.in
}

Table of contents

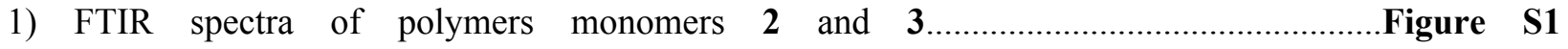

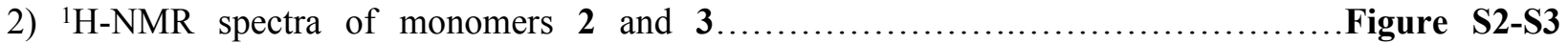

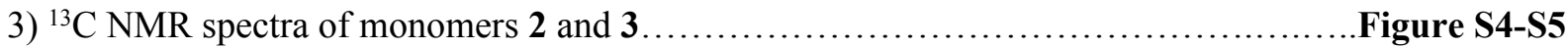

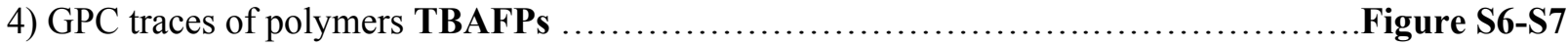

5) Solubility Chart of polymers TBAPs in various solvents............................... Table S1

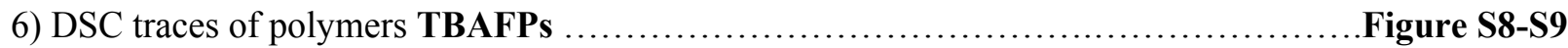

7) First-order rate constant for trans-cis photoisomerization of TBAFPs...................Figure $\mathbf{S 1 0}$

8) Change in the quantum yield value of TBAFPs upon photoisomerization .............. Figure S11

9) Absorbance titration of TBAFPs with incremental addition of picric acid ............. Figure S12 


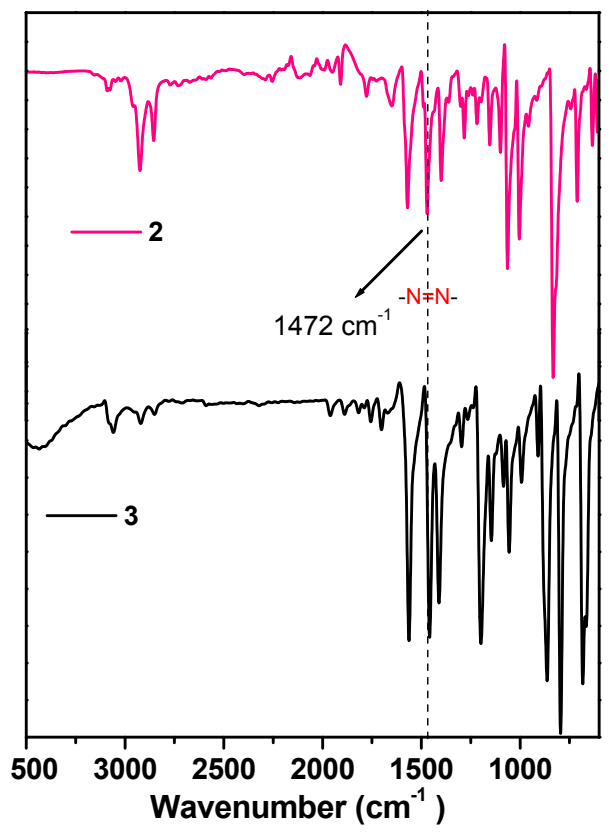

Figure S1: FTIR spectra of monomers: para-dibromo azobenzene (2) and meta-dibromo azobenzene (3)
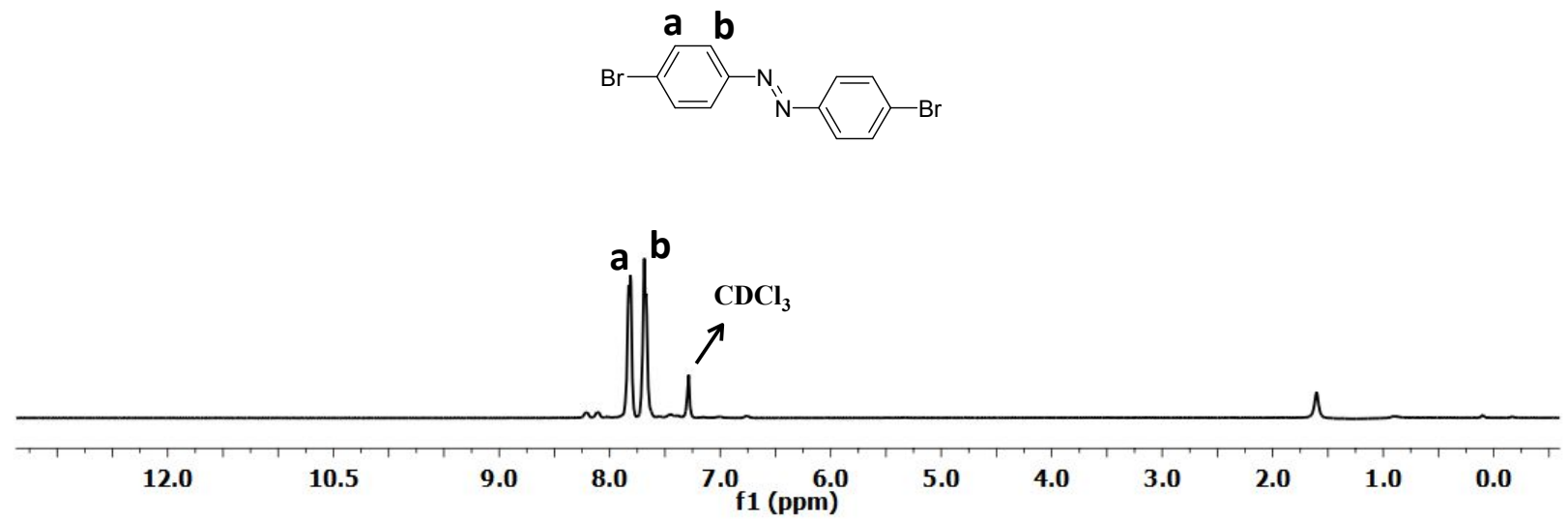

Figure S2: ${ }^{1} \mathrm{H}-\mathrm{NMR}$ spectra of monomer 2 

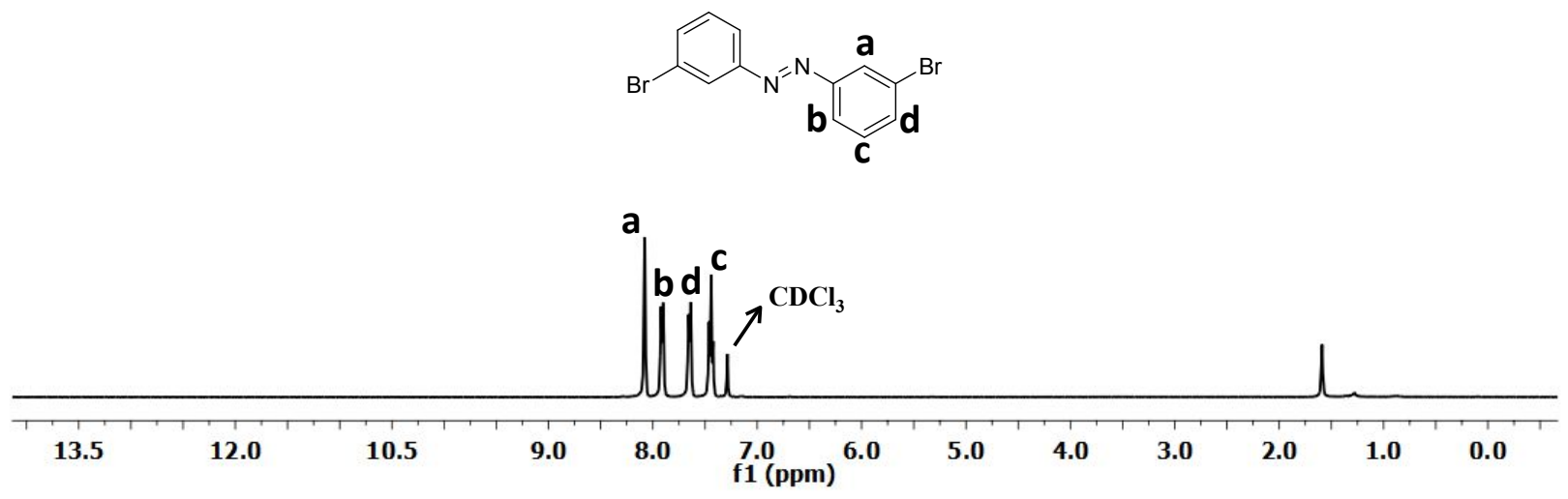

Figure S3: ${ }^{1} \mathrm{H}-\mathrm{NMR}$ spectra of monomer 3

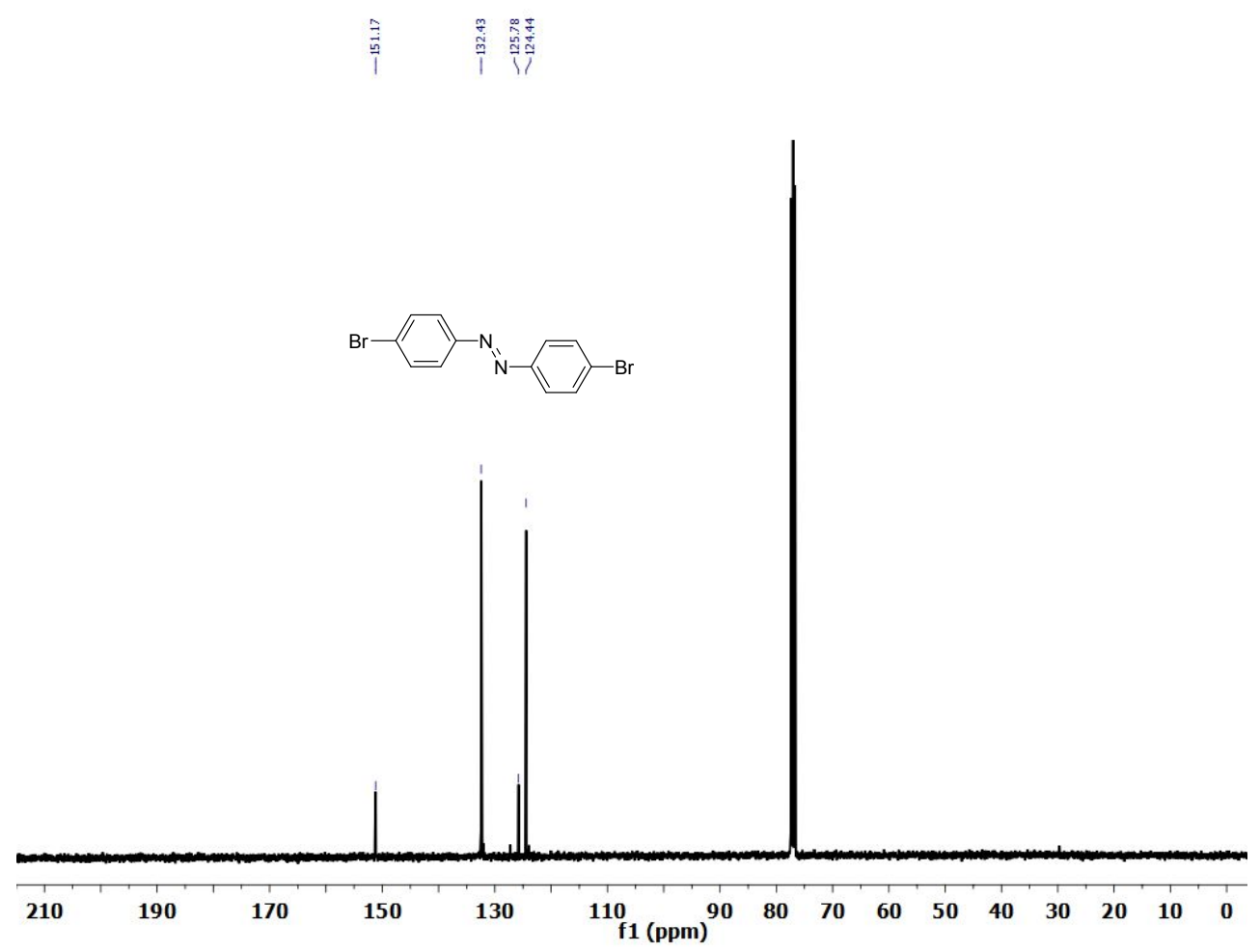

Figure S4: ${ }^{13} \mathrm{C}-\mathrm{NMR}$ spectra of monomer 2 


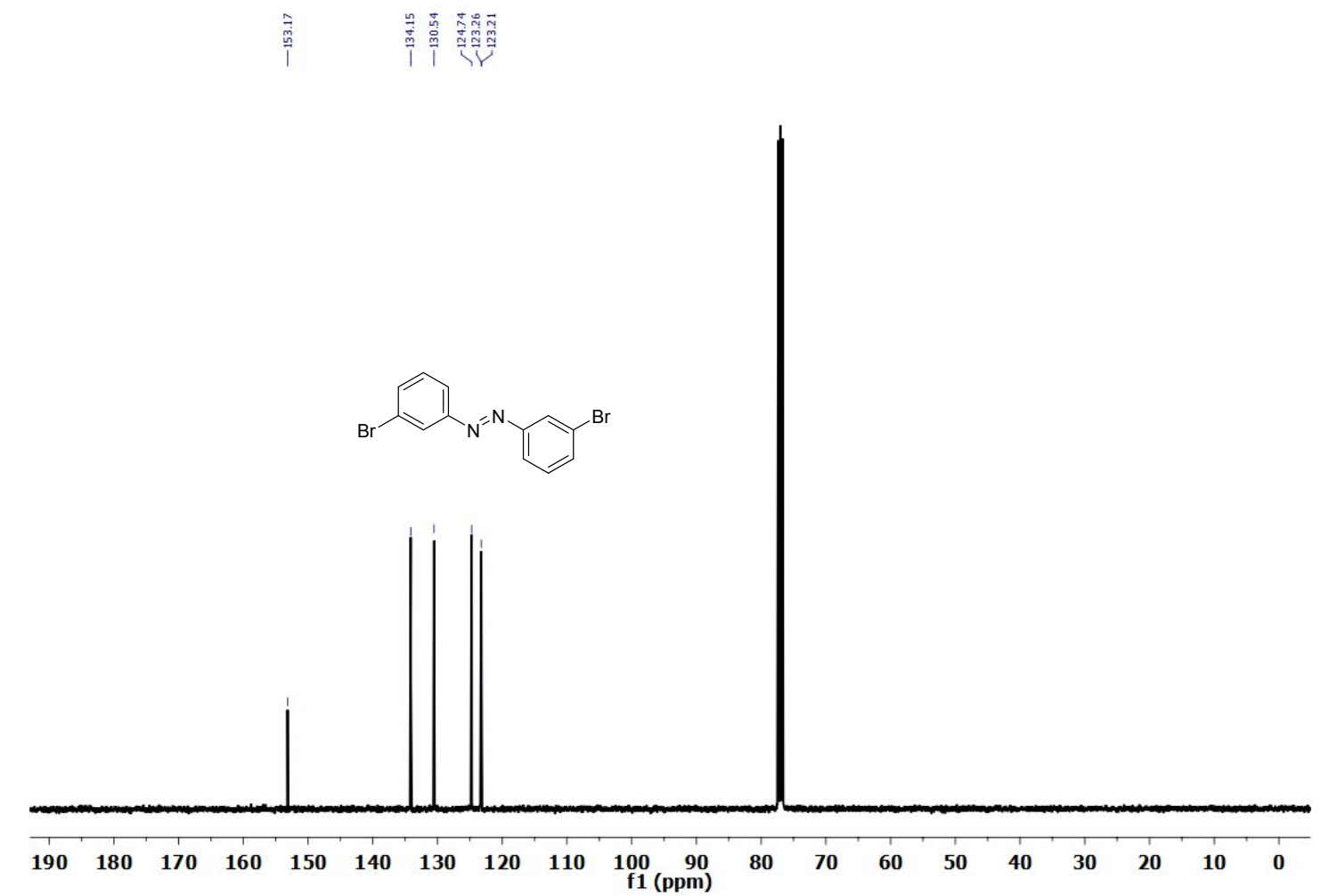

Figure S5: ${ }^{13} \mathrm{C}-\mathrm{NMR}$ spectra of monomer 3

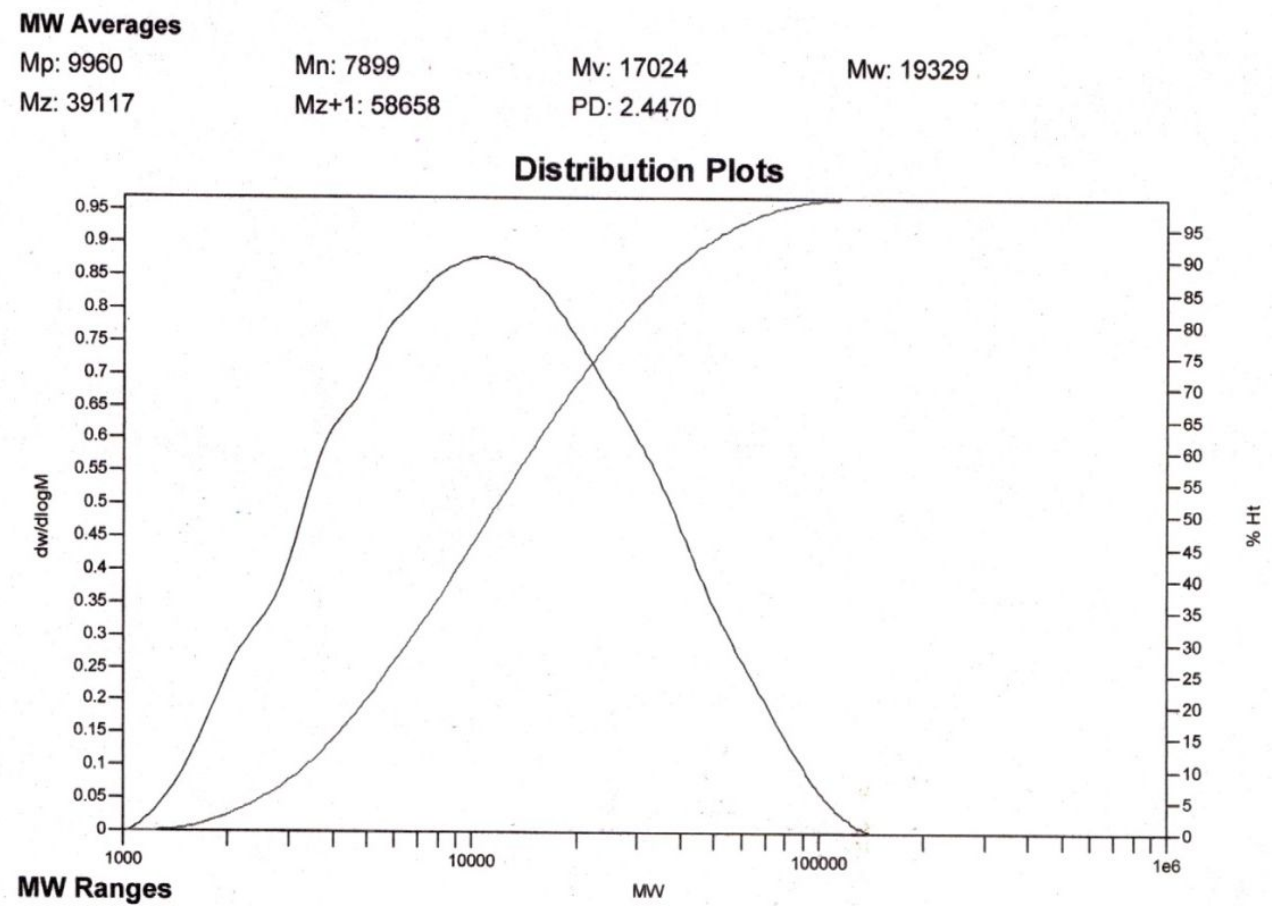

Figure S6. GPC trace of polymer TBAFP1 


\section{MW Averages}

Mp: 4775

Mz: 22818

Mn: 4273

$\mathrm{Mz}+1: 34033$
Mv: 9535

PD: 2.5530

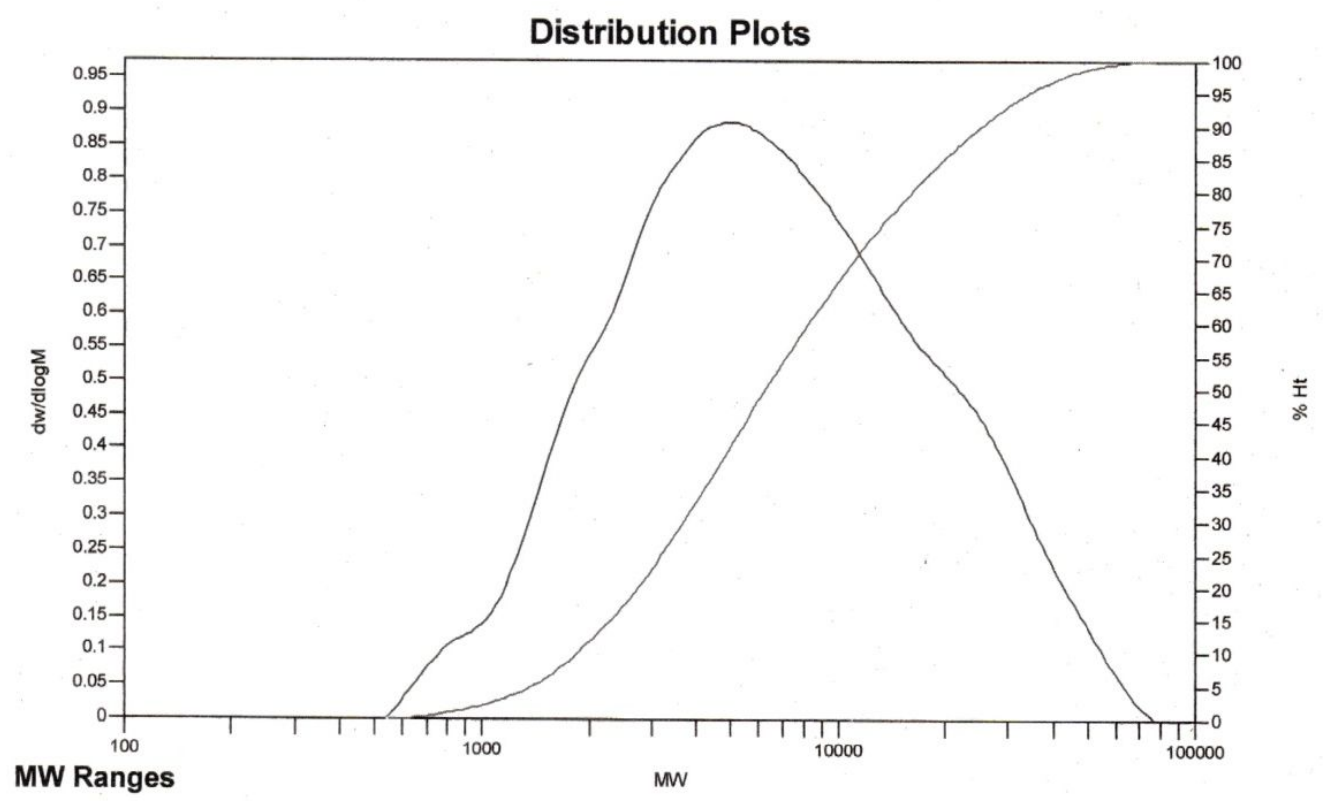

Figure S7. GPC trace of polymer TBAFP2

Table S1: Solubility Chart of polymer TBAFP1 and TBAFP2 in various Solvents ${ }^{\mathrm{a}}$

\begin{tabular}{|l|l|l|l|l|l|l|l|l|c|c|}
\hline Polymer & $\mathrm{CHCl}_{3}$ & DCM & DMF & $\mathrm{CH}_{3} \mathrm{OH}$ & Acetone & THF & Toluene & DMSO & $\mathrm{CH}_{3} \mathrm{CN}$ & $\begin{array}{l}\text { Ethyl } \\
\text { acetate }\end{array}$ \\
\hline TBAFP1 & + & + & + & - & - & + & + & + & + & - \\
\hline TBAFP2 & + & + & + & - & - & + & + & + & + & - \\
\hline
\end{tabular}

a Solubility measured at a polymer concentration of $0.02 \mathrm{~g} / \mathrm{mL} .(+)$ soluble at room temperature, $(-)$ insoluble on heating. DCM: dichloromethane; DMF: N,N-dimethylformamide; THF: tetrahydrofuran DMSO: dimethyl sulfoxide. 


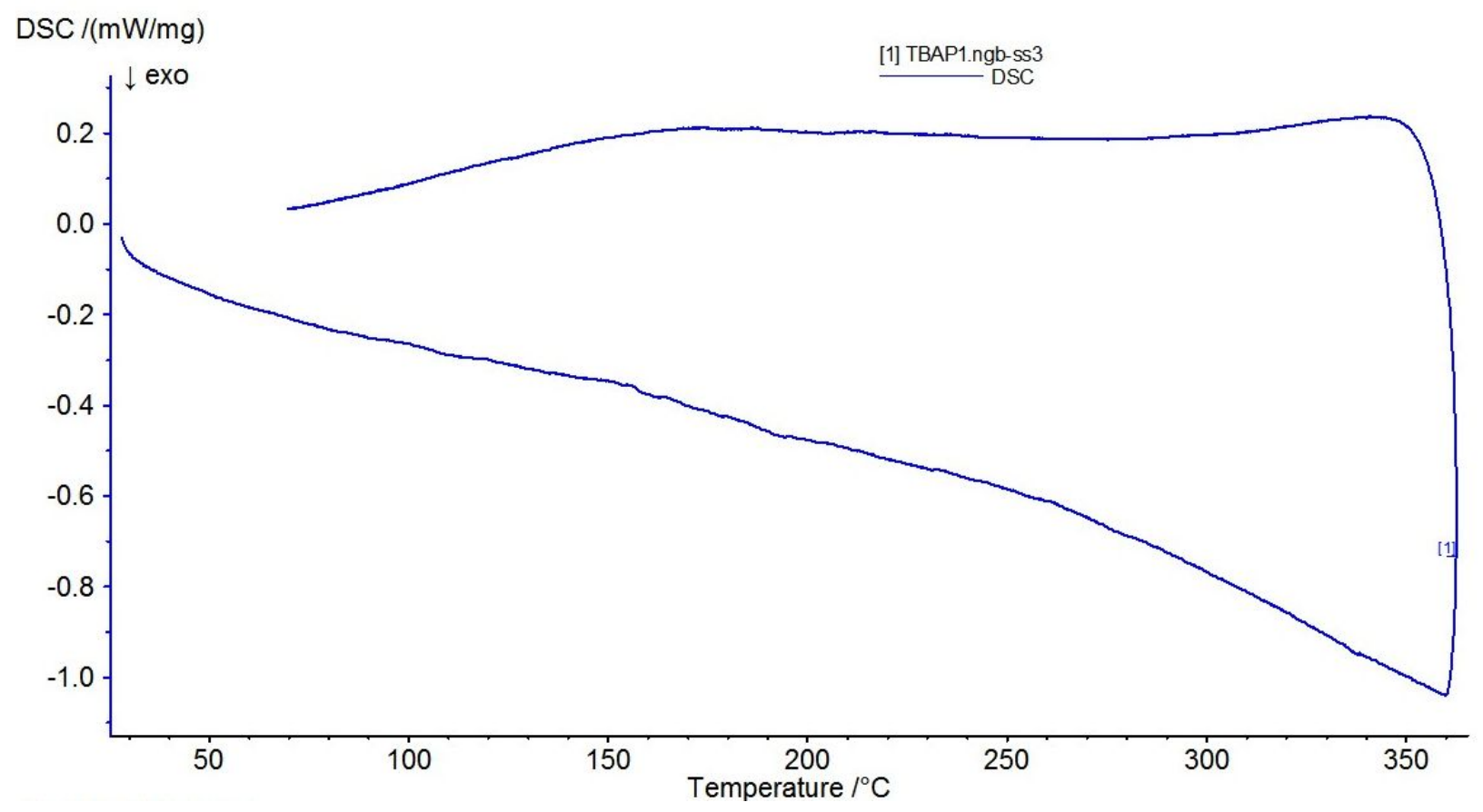

Figure S8. DSC of polymer TBAFP1

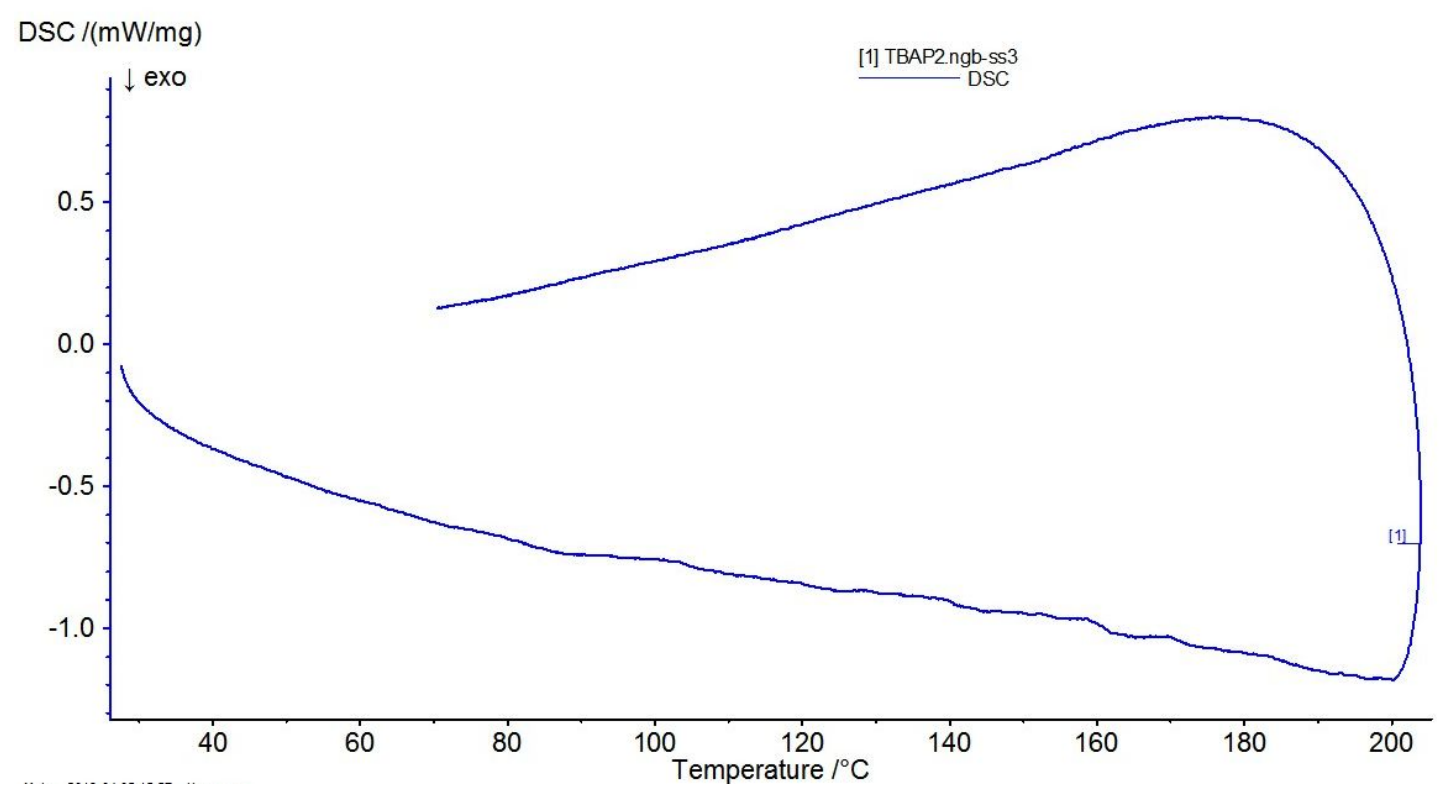

Figure S9. DSC of polymer TBAFP2 

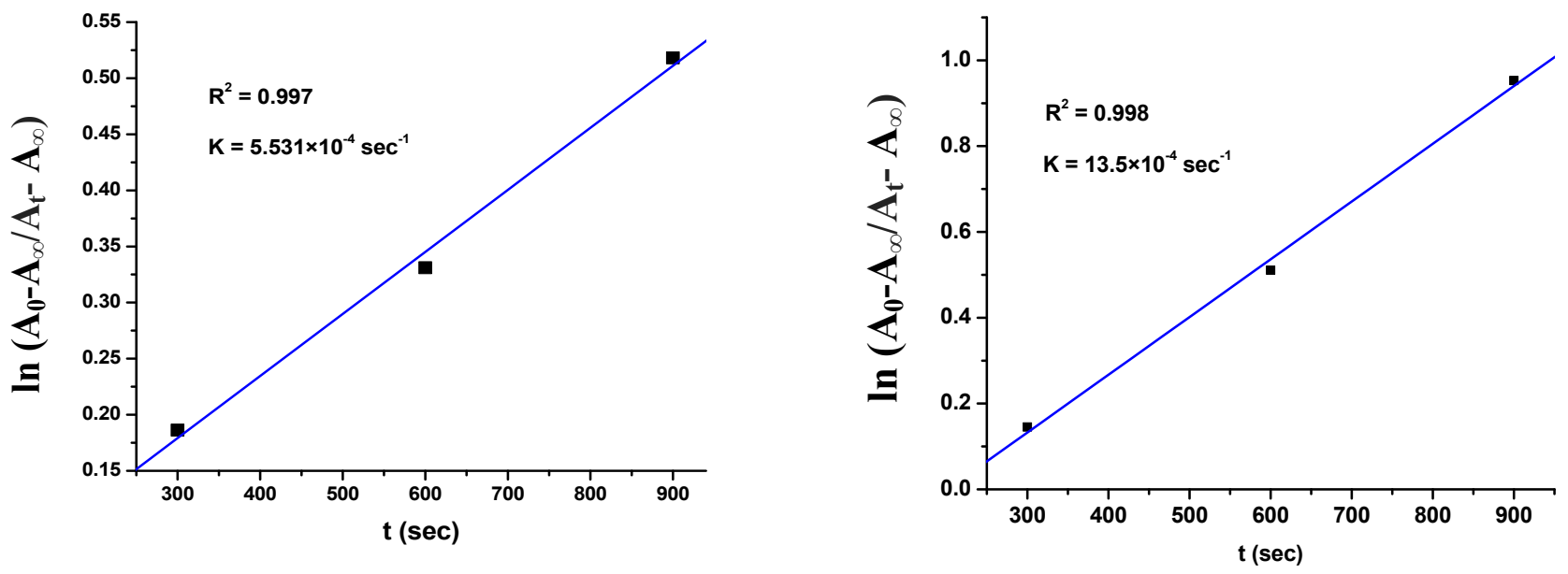

Figure S10. First-order rate constant for trans-cis photoisomerization of polymer TBAFP1 and TBAFP2
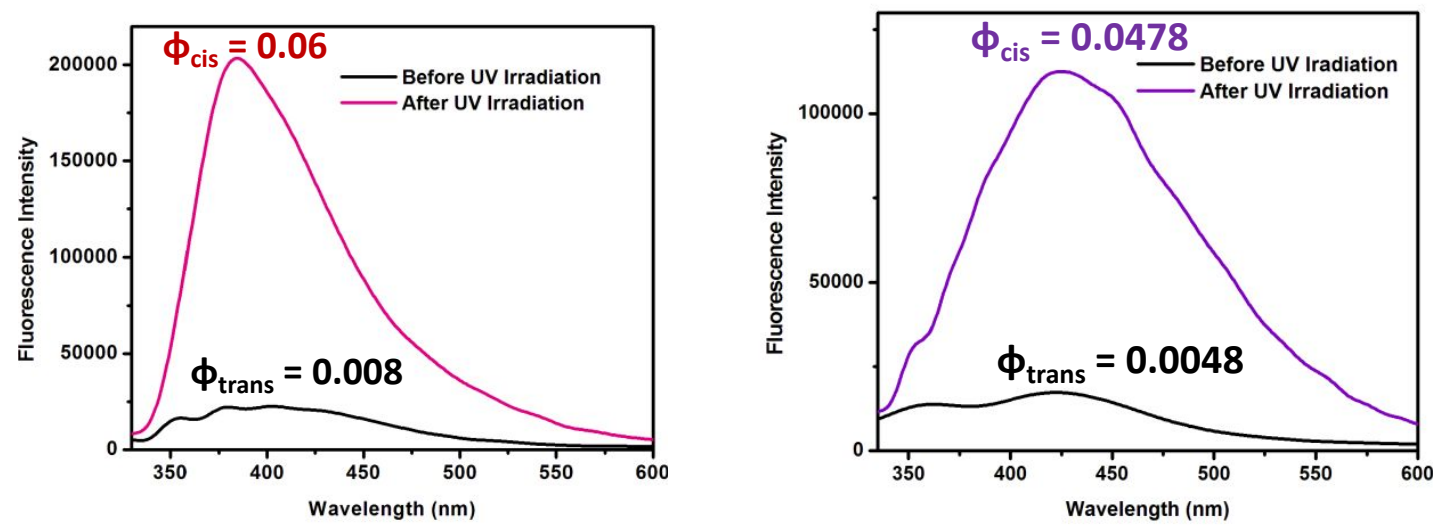

Figure S11. Change in the quantum yield value of TBAFPs upon photoisomerization. 

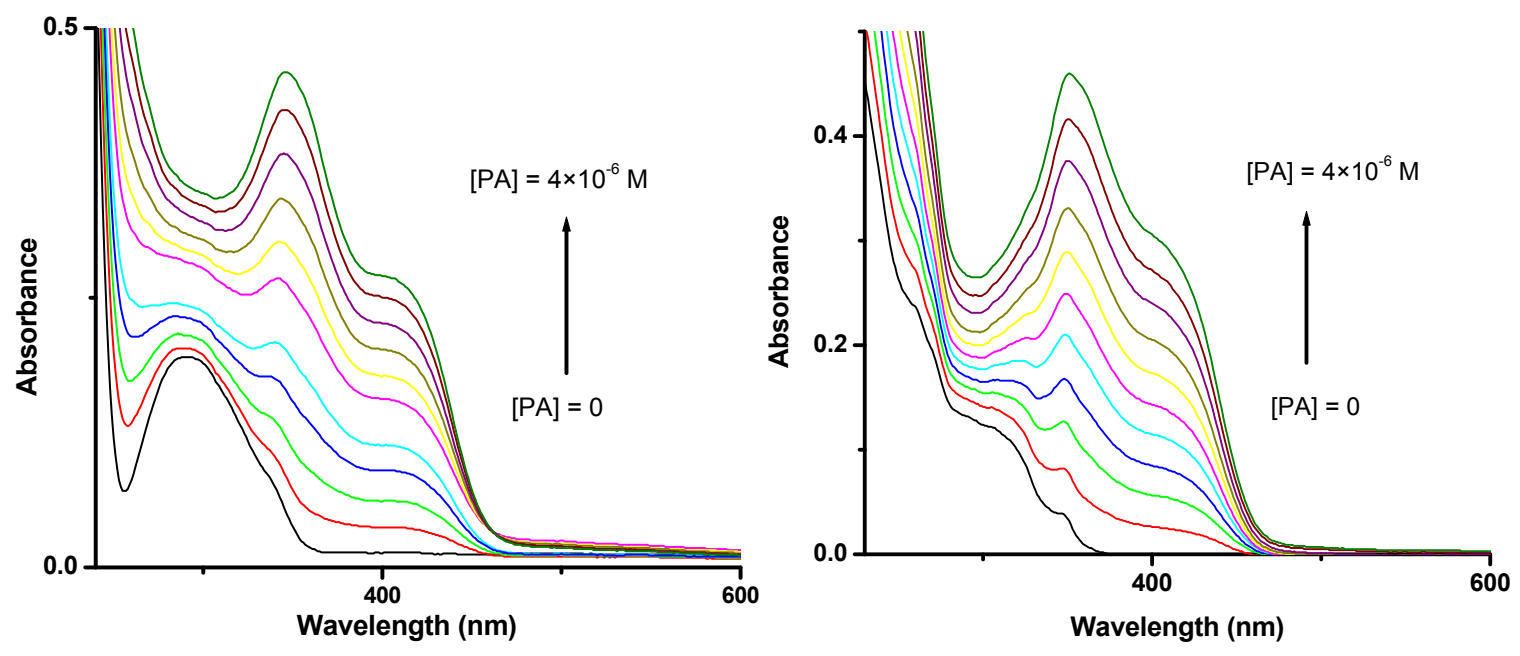

Figure S12. Absorption titration of TBAFPs with incremental addition of picric acid. 